\title{
Introduction
}

\section{State-of-the-Art Telemedicine/Telehealth: An International Perspective}

\author{
RASHID L. BASHSHUR, Ph.D., ${ }^{1}$ SALAH H. MANDIL, Ph.D., ${ }^{2}$ \\ and GARY W. SHANNON, Ph.D. ${ }^{3}$
}

$\mathbf{T}$ HIS REPORT IS THE PRODUCT of a symposium entitled, "State-of-the-Art Telemedicine / Telehealth: An International Perspective," convened at the University of Michigan in August 2001. More than 200 participants took part in a series of formal presentations, panel discussions, and workshops/forums. (See the List of Participants on pages 109-110). Invited speakers, panel members, and other participants represented the leaders in experience and achievement in telemedicine/telehealth, ${ }^{\text {a }}$ science, technology, and program and policy development and application. In addition to a comprehensive representation from the diverse sectors of telemedicine, speakers and participants reflected the international interest in telemedicine. Participants came from North and South America, Europe, Africa, Asia, and the Middle East. They represented telemedicine efforts underway or proposed in universities, medical centers and programs as well as in the private, public, and military sectors.

The diversity of participants is also reflected in the Symposium's cosponsors and supporters. The University of Michigan and the World Health Organization cosponsored the event. Other U.S. organizations providing support included the National Aeronautic and Space Administration (NASA), National Library of Medicine (NLM), Office for the Advancement of Telehealth (OAT), Agency for Health Care Research and Quality (AHRQ), Department of Commerce Technology Opportunity (TOP), U.S. Army Telemedicine and Advanced Technology Research Center (TATRC), RGK Foundation, Salinas Valley Memorial Health System, Internet2, and Environmental Research Institute of Michigan (now Altarum). ${ }^{\mathrm{b}}$

Although from diverse interest and geographical backgrounds, participants in the symposium focused on two primary purposes:

\footnotetext{
${ }^{1}$ Director of Telemedicine, University of Michigan Health Center, Ann Arbor, Michigan.

${ }^{2}$ Director, HIT, World Health Organization, Geneva.

${ }^{3}$ University of Kentucky, Lexington, Kentucky.

a Acknowledging the debate over the terminology related to the use of various electronic communication modalities and the diverse health and health care-related content of the expanding field, the term "telemedicine" will be used throughout the report only in order to make the discussions more concise, and it includes telehealth. Broadly defined, "Telemedicine involves the use of modern information technology to deliver health services to remote patients and to facilitate health information exchange between providers and/or clients at some distance from each other. A telemedicine system is an integrated health care network offering comprehensive health services to a defined population through the use of telecommunications and computer technology." 1

${ }^{b}$ The support of all these organizations and agencies is gratefully acknowledged. However, the findings, views, and perspectives presented in this entire report are those of the authors and editors, and not necessarily those of the sponsors.
} 
(1) to assess the state-of-the art in telemedicine and (2) to arrive at a set of recommendations and action plans that, if enacted, set the stage for a robust and directed move forward for telemedicine at the regional, national, and international levels.

\section{THE SYMPOSIUM}

The symposium was organized into a progressive series of formal presentations, panel discussions, workshops, and a summary plenary session. Workshop participants were assigned on the basis of their respective interest and expertise, and included those who made formal presentations and participated in panel discussions on the selected topics. Reports were derived for the following topics: network organizational models, technology development and application, clinical applications, public health, disease surveillance and personal health, education, and telemedicine diffusion. It is hoped that the symposium's organization, focus, and agenda make it unique and, more importantly, make this report critical to a well-conceived advancement of telemedicine based on the best information available.

More specifically, the symposium had several related objectives. The first was to convene an international gathering based on invited position papers prepared and presented by leading experts in the field of telemedicine. A second objective involved examining and assessing the "state-of-the-art" of telemedicine. Based on these first two objectives, the third objective was to achieve a consensus on the major issues facing the development and diffusion of telemedicine. The fourth and, perhaps most critical, objective was to propose recommendations for research agendas and action plans directed toward moving telemedicine forward in the service of improving health and medical care at regional, national, and international levels.

\section{THE REPORT}

This report addresses selected critical aspects of telemedicine. It focuses on issues related to the development of integrated regional, national, and international networks; clinical ap- plications of telemedicine as well as the application of telemedicine in public health, disease surveillance, personal health, and health education sectors; telemedicine technology; and the diffusion of telemedicine.

Accordingly, the report is organized into topical chapters, as follows.

- Chapter 1 provides a brief introduction to the evolution of telemedicine and its role in the health care system.

- Chapter 2 provides a general assessment of clinical telemedicine applications and a discussion of clinical applications in various stages of development.

- Chapter 3 examines the role of telemedicine in public health, epidemiological surveillance, and health promotion/disease prevention.

- Chapter 4 focuses on the role of telemedicine in medical education.

- Chapter 5 examines the role and development of regional, national and international telemedicine network models and reviews several alternative models.

- Chapter 6 focuses on issues pertaining to telemedicine technology.

- Chapter 7 examines issues pertaining to the diffusion of telemedicine.

- Chapter 8 concludes the report and provides a general summary and conclusions.

Each chapter concludes with a series of recommendations pertaining to research needs, related research agenda, and recommended action.

\section{REFERENCE}

1. Bashshur, R. Telemedicine and the Health Care System. In: Bashshur R, Sanders J, Shannon G, eds. Telemedicine Theory and Practice. Springfield, IL: Charles C Thomas, 1997;9.

Address reprint requests to: Rashid L. Bashshur, Ph.D. Director of Telemedicine University of Michigan Health System C201 Medinn Building 1500 East Medical Center Drive Ann Arbor, MI 48109-0825

E-mail: bashshur@umich.edu 